\title{
The Perils of Seeking Financing at the Wrong Time
}

\section{Phil Greenwood (University of Wisconsin - Madison)}

\section{KEYWORDS: Management of Companies \& Enterprises, Entrepreneurship, Finance, Negotiation.}

The timing of external funding for a new venture can have dramatic impact on its survival and success. In the case of equity financing (i.e., preferred and/or common stock), seeking funding before it's needed could mean the entrepreneur/founding team gives up more ownership than necessary. In the case of debt financing, a venture may have obtained a bank loan before the company is able to pay back interest and principal.

On the other hand, not raising enough money at the right time can potentially lead to disaster, with the early stage venture heading towards the "cliff" when running out of cash. More importantly, when investors sense that the company is "running on fumes" or out of cash, they they can strong-arm the company and its founders in their negotiations.

A common thought process when fundraising isthe best time to raise money is when you can.$^{[1]}$ The early-stage investment decision is more art than science as market changes, economic shifts or other more exciting opportunities can lead an investor to lose interest in the current deal in favor of more "exciting" ones. And as this past decade has shown, the startup environment has experienced quickly changing economic and market conditions that radically affect both the ability to raise money and the valuations and terms of received when offered.

Here's an example of how external events can impact fundraising. In summer 2001, an analytical instrument company located in the Midwest estimated that to speed development on its proprietary technology for the semiconductor market, they would need $\$ 5$ million in the next round of financing. Spurred by great progress and lots of attention, the company decided to start seeking money in August of 2001. The September 2001 terrorist attacks occurred not long after they started the fundraising process and stalled their ability to raise funds for at least six months. In addition, the overall stock market declined, directly depressing valuations for early-stage companies.

\section{Burn Rate and Time-to-Cliff}

Most companies seek financing to avoid running out of cash. Early-stage ventures should consider how much of a cash cushion they need to avoid running out: in other words, the proper amount of "runway" -- cash on hand -- for their needs.

How large a cushion? That depends on the industry and the product development time cycle it takes from the idea stage to revenue stage. For instance, in the life science industries, where the time from idea generation to market launch may be a decade or more, a company may determine it needs two or three years of cash on hand. In the computer software industry, Bill Gates, when he and Paul Allen first funded Microsoft, believed that the company needed at least 12 months of cash on hand. The "Twelve Month Cash-on-Hand" rule-of-thumb is common for firms in non-life science industries. Regardless of which level a firm feels comfortable with, the common method to estimate the level of cash in relation to time is its Burn Rate and its Time-to-Cliff (TTC).

The concept of the burn rate is straightforward:

- Cash Burn Rate = "Net Cash Expenditures" over a relevant period divided by the \# of Days, Weeks or Months in that period

The Burn Rate provides financiers with an estimate of how much is being spent on a daily, weekly, monthly or annual basis. In determining the Net Cash Expenditures, the firm's cash flow statement, income statement and balance sheet provide the sources of the data. If the firm utilizes the "accrual method" of accounting (an accountant can provide a detailed explanation), the Net Cash Expenditures is defined as (using what is called the Indirect Method, which starts with Net Income or Loss and adjusts from changes in Balance Sheet accounts):

- Net Cash Expenditures = Net Income + 
Depreciation and Amortization Expenses Increase in Net Working Capital - Increases in Non-Current Assets + Increases in Non-Current Liabilities

\section{How it Works}

As a hypothetical example, Cool Bean Coffee House is a small coffee establishment located near a Midwest university (See Appendix following article). The Cool Bean, popular among graduate students, was established in 2011 and has developed into a stable, independent shop offering coffee, tea and desserts. The co-owners, a husband and wife, earn a nice income from the business and don't have any major growth plans.

In 2015 and 2016, the Cool Bean experienced cash flow issues with little knowledge of the causes. As with many small businesses, the Cool Bean owners were confused since their CPA consistently advised that the company was profitable and "not to worry" (Net Income of $\$ 130$ thousand and \$202 thousand for the years 2015 and 2016, respectively). Yet, the cash balance dwindled to $\$ 16$ thousand at the end of 2016 on the balance sheet. An analysis of the Net Cash Expenditures provided significant clarity about the company's financial issues.

Table 1 - Cool Bean, Net Cash Expenditures and Cash Flow, 2016 (in $\$ 000$ 's)
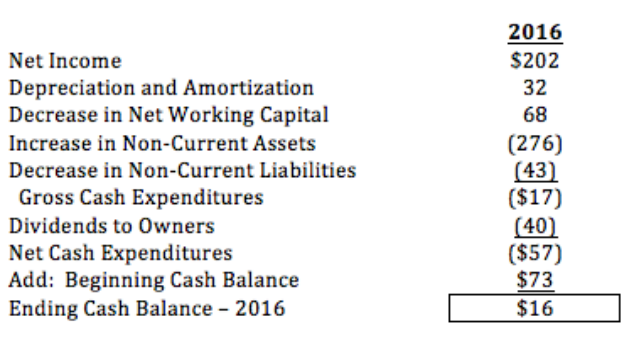

The Net Cash Expenditures highlights where the cash has flowed, leading to the draining cash balance despite accounting profits. Cool Bean acquired a significant amount of Fixed Assets (\$276 thousand) primarily in Machinery and Equipment (see Balance Sheet in Appendix). The asset purchases were partially financed by a decline in Working Capital but primarily came from cash balances. Based on Net Cash Expenditures of $\$ 57$ thousand in 2016, Cool Bean's Burn Rate (on a gross basis) would equate to $\$ 57$ thousand/12 months or approximately $\$ 5$ thousand per month.
Calculating the Net Cash Expenditures and Burn Rate are the first steps in evaluating how long the cash on hand will last. In other words, one can estimate the venture's TTC calculation or how much time the firm has left before it runs out of cash. The TTC is calculated as:

- Time to Cliff = Cash on Hand divided by Burn Rate

In Cool Bean's case, their TTC would approximate just over 3 months (2016 Cash Balance of $\$ 16$ thousand/Burn rate of $\$ 5$ thousand per month). In other words, Cool Bean is close to running out of cash without making changes.

What could Cool Bean do (could have done) before seeking outside financing from a banker or equity investor? The goal is to reduce the burn rate to a "build rate" (i.e., generate cash). First, the coffee house could improve profitability by raising prices, increasing volume, and/or optimizing its cost structure. However, the company appears plenty profitable so there may not be as much flexibility with Profit and Loss management.

Second, Cool Bean should manage its Net Working Capital more effectively to increase cash flow. Such steps could be to reduce Accounts Receivable, lower Inventory levels, and/or lengthen the Accounts Payable amounts by increasing days it takes to pay vendors (this would have to be weighed against potential lost discounts). (Author's note: Most companies have little flexibility in managing their Non-Accounts Payable, aka Accrued Liabilities, as they usually relate to Employee Salaries/Wages, Income Taxes Payable, etc.)

Third, in this case, they could evaluate their Capital Expenditure process. Maybe the company could lease some of the equipment? Could they try to bootstrap their purchases by seeking second-hand equipment or bartering? Finally, could the owners delay some purchases?

Finally, Cool Bean could examine their dividends paid to owners. Could dividends be deferred or eliminated? Are there other ways to compensate the owners without expending cash (maybe increased stock, etc.)?

By monitoring and managing its Burn Rate and TTC metrics, Cool Bean can obtain greater control over its financing needs. By taking steps to extend run rate (i.e., 
extend the TTC) Cool Bean can reduce, delay or even eliminate the need for external financing. By doing so, owners of small businesses can maintain greater control of their enterprise, a goal of most entrepreneurs.

\section{Burn Rate and TTC - Importance of Forecasting}

One caveat to Burn Rate and TTC calculations is that business owners should base them on future financial activity rather than historical data. Early stage firms can be in major growth modes at varying stages of the firm's life cycle. When growth occurs, it's not unusual for burn rates to double or triple as the firm increases expenditures for new hires, purchase of machinery, new space, etc.

Gilead Sciences, one of the major biotech success stories during the past 20 years, is one example of a company in later stages of development that placed much emphasis on the cash flow metrics. In the early 1990's, despite having over $\$ 10$ million of cash on hand, Gilead was planning its next growth stage seeking financing either through private equity or an Initial Public Offering.

At the time, Gilead maintained a policy of possessing 24-36 months of cash on hand at any one time. At its historical Cash Burn Rate (the previous 12 months of operations), their TTC was in the 12-to-18 month range. However, since they were going to have hire sales reps, increase marketing and add other critical resources, their historical monthly burn doubled: from $\$ 300$ thousand per month to a projected $\$ 750$ thousand. At present cash levels, their Time-to-Cliff was just over 12 months, well below their goals. Accordingly, Gilead readjusted its ongoing cash needs to $\$ 25-\$ 40$ million, hoping to increase cash levels to their desired TTC of 24 months or more

\section{Conclusion}

The Burn Rate and TTC are the most important financial metrics for an early stage venture that does not generate sales and/or profits. The TTC and Burn Rate guide the founding team in their management decisions, especially in determining whether they need external financing, how much they need, and the best timing for it. Entrepreneurs should guard this information very closely, sharing it only with trusted stakeholders, because active/aggressive investors, once they understand Burn Rate and TTC, can use them as leverage in their negotiations.

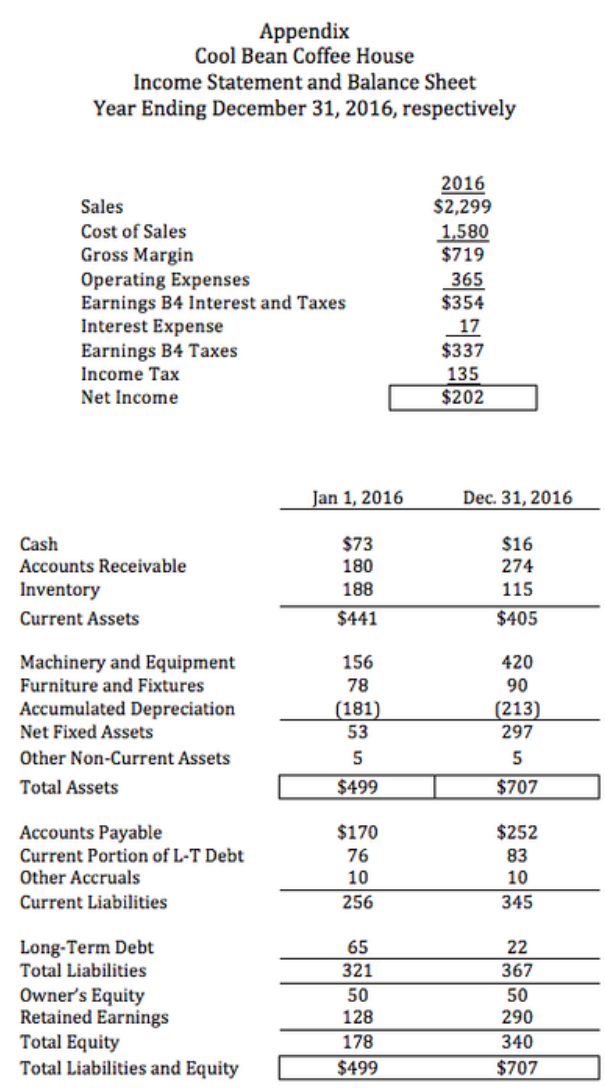

[1] Mark Peter Davis blog, "The Best Time to Raise MoneyisWhen YouCan."(https://mpd.me/the-best-timeto-raise-money-is-when-you-can-b05ceb87ef56)

Additional Search Terms: funding my startup, funding my venture, looking for investors, investment, funding my company, getting cash 